\title{
Evidence of Malignant Disease Description
}

National Cancer Institute

\section{Source}

National Cancer Institute. Evidence of Malignant Disease Description. NCI Thesaurus.

Code C161312.

A description of the basis for the determination that a malignancy is present. 